Fordham University

Fordham Research Commons

2016

\title{
Nonstandard Parental Employment Schedules and Father Involvement
}

Matthew Weinshenker

weinshenker@fordham.edu

Follow this and additional works at: https://research.library.fordham.edu/soc_facultypubs

Part of the Family, Life Course, and Society Commons, and the Work, Economy and Organizations Commons

\section{Recommended Citation}

Weinshenker, Matthew, "Nonstandard Parental Employment Schedules and Father Involvement" (2016). Sociology Faculty Publications. 20.

https://research.library.fordham.edu/soc_facultypubs/20

This Article is brought to you for free and open access by the Sociology at Fordham Research Commons. It has been accepted for inclusion in Sociology Faculty Publications by an authorized administrator of Fordham Research Commons. For more information, please contact considine@fordham.edu, bkilee@fordham.edu. 
Nonstandard parental employment schedules and father involvement

Matthew Weinshenker

Department of Sociology \& Anthropology, Fordham University, Bronx, NY, USA

Address correspondence to: Matthew Weinshenker, Department of Sociology \& Anthropology, Fordham University, 441 East Fordham Road, Bronx, NY 10458, USA. Telephone: (718) 817-0724. Fax: (718) 817-3846. Email: weinshenker@ fordham.edu.

This article was published in Community, Work \& Family, 19:4, 396-413, DOI:10.1080/13668803.2015.1074544. The final publication is available at https://www.tandfonline.com/doi/full/10.1080/13668803.2015.1074544. 


\title{
Nonstandard parental employment schedules and father involvement
}

\begin{abstract}
This study assesses the impact of nonstandard employment schedules (shift work) on parenting among U.S. fathers of young children in dual-earner couples. The outcomes examined include total caregiving, caregiving without the mother present, and the elements of father involvement proposed by Pleck: positive engagement, warmth, and control. Models with latent variables and with lagged dependent variables are estimated using three waves of nationally-representative data from the Early Child Longitudinal Study - Birth Cohort (ECLS-B). The results indicate that employment scheduling mainly shapes the context in which involvement takes place. Compared to dual-earner couples who are each employed during the day, fathers in couples in which at least one parent has a nonstandard schedule tend to care for their children more in the mother's absence. To a more limited extent, they also do more caregiving overall. These effects are most conclusively found when the father works during the day and the mother works during the evening, when the mother works during the day but the father works a night, split, rotating, or other shift, and when both parents have nonstandard schedules. Parental work schedules, however, have little impact on father involvement aside from care.
\end{abstract}

Keywords: shift work, fathers, father involvement, child care 
According to recent national data, roughly one-fifth of the U.S. workforce is employed on nonstandard schedules, such as evening, night, rotating, and split shifts (Alterman, Luckhaupt, Dahlhamer, Ward, \& Calvert, 2013). Among dual-earner parents of young children, "shift work" frequently results in partially or completely non-overlapping employment schedules, with each parent at home at times when the other is on the job (Presser, 2003). It is therefore not surprising that parental nonstandard employment has consistently been found to increase the likelihood that fathers care for their children in the mother's absence (Brayfield, 1995; La Valle, Arthur, Millward, Scott, \& Clayden, 2002; Pagnan, Lero, \& Wadsworth, 2011; Presser, 2003; Rapoport \& Bourdais, 2008; Wight, Raley, \& Bianchi, 2008).

Much less is known about the effect of nonstandard parental work schedules on other aspects of men's parenting. This study investigates the impact on the components of Pleck's (2010) conception of paternal involvement, including positive engagement, warmth, and control. Understanding the relationship between nonstandard schedules and involvement is valuable because parental shift work is associated with negative child socio-emotional and cognitive outcomes (Han, 2005, 2008; Heyman, 2000; Joshi \& Bogen, 2007; Rosenbaum \& Morett, 2009; Strazdins, Clements, Korda, Broom, \& D'Souza, 2006). Father involvement, by contrast, has frequently been shown to enhance child outcomes. (For reviews of the literature, see Parke, 2002; Pleck \& Masciadrelli, 2004.) It is therefore important to know what contexts (such as child ages and specific work schedules) lead to increased father involvement when one or both parents are shift workers.

This study assesses the impact of five kinds of parental nonstandard employment arrangements (shift work) on care and on positive involvement among fathers of young children in dual-earner couples in the U.S. Models with latent variables and with lagged dependent variables are estimated using nationally-representative data from the Early Child 
Longitudinal Study - Birth Cohort (ECLS-B). The results indicate that, compared to couples who are each employed during the day, fathers in couples in which at least one parent has a nonstandard employment schedule tend to care for their children more in the mother's absence and, to a more limited extent, to do more caregiving overall, but not to be more involved in other ways.

\section{Background}

\section{Employment Scheduling and Child Development}

This study draws on concepts from the ecological approach to human development, which calls attention to the way that multiple, interlocking social systems affect children's development (Pleck, 2007). Relationships with significant figures in a child's life interactional microsystems - have the most immediate influences on development (Bronfenbrenner, 1994). These microsystems are shaped by, among other things, social settings in which events influence the child even though he or she does not participate in them (the exosystem). Because events at work can "spill over" to affect parents' mood and behaviour in the home in both positive and negative ways (Bellavia \& Frone, 2004), the parental workplace is an important element of the exosystem.

Employment scheduling, as already discussed, is diverse in the contemporary United States. Scholars have found that children's well-being can differ depending on their parents' schedules, with many reporting a negative impact of shift work on cognitive development and educational outcomes (Han, 2005; Heyman, 2000) and on socio-emotional well-being (Han, 2008; Joshi \& Bogen, 2007; Rosenbaum \& Morett, 2009; Strazdins et al., 2006).

There are likely to be multiple pathways by which nonstandard hours harm children's well-being, including its negative impacts on parents' mental health and their relationship quality (Strazdins et al., 2006). This investigation focuses on another factor: parental 
involvement in children's lives. To take mothers first, evening work, which is the most common kind of nonstandard employment, has been found to reduce the amount of time with children (Presser, 2003; Wight et al., 2008). The quality of parenting may also be affected, as suggested by studies of young children (Grzywacz, Daniel, Tucker, Walls, \& Leerkes, 2011) and of adolescents (Davis, Crouter, \& McHale, 2006).

\section{Employment Scheduling and Father Involvement}

Because they spend less time with children than mothers do on average (Pleck, 2010), fathers have more potential to increase their involvement, rather than reduce it, as a result of nonstandard employment. Indeed, the literature has found that parents' nonstandard work hours increase use of father care (Brayfield, 1995; La Valle et al., 2002; Presser, 2003) or time spent caring (Pagnan et al., 2011; Rapoport \& Bourdais, 2008; Wight et al., 2008).

One explanation is that couples actively choose non-overlapping hours in order to practice "tag-team parenting" (Hattery, 2001), ensuring parental care for the children around the clock. In the few data sources which contain information about individuals' decisions to work nonstandard hours, some people do, in fact, report seeking them out for this reason (Fox, Han, Ruhm, \& Waldfogel, 2013; Presser, 2003). However, other couples stagger their work schedules and share care because of constraint rather than choice. Many shift workers are young, are racial minorities, and lack educational credentials; individuals with these characteristics may be forced to work nonstandard hours owing to a lack of other available jobs (Enchautegui, 2013). Others choose nonstandard work to earn better pay, or for additional reasons unrelated to caregiving (La Valle et al., 2002; Presser, 2003). It is likely that choice and constraint each account for part of the association between non-overlapping schedules and father care, with both forces working together in some families (Pagnan et al., 2011), but that constraint plays a role in a larger number of cases. 
Regardless of the rationale, if the father is home when the mother is at work, the principle of time availability (Coverman, 1983) predicts that he will be likely to provide care. The theory also predicts that the amount of father care will increase if other options (e.g. paid care) are not available, as is more often the case in the evening and at night. This is consistent with past empirical research which has shown that father care is most frequent when the mother works a nonstandard schedule, such as an evening or night shift, while the father who works during the day is at home (La Valle et al., 2002; Presser, 2003).

This study investigates the impact of parental shift work not only on fathers' care for young children, but also on their involvement broadly conceived. As defined by Pleck (2010), father involvement has three core components:

(1) positive engagement, which is "interaction with the child of the more intensive kind likely to promote development" (Pleck, 2010, p. 61);

(2) warmth and responsiveness; and

(3) control, a multifaceted concept that includes monitoring, limit-setting, and participation in making important decisions about the children. Participation in decisions is conceptualized as an aspect of control because of the expectation that young children's well-being is enhanced when fathers take responsibility for ensuring their needs are met.

As Pleck details, each of these three dimensions have well-established links to child wellbeing, the latter two in the construct of authoritative parenting.

Is there reason to expect parental work scheduling to affect the components of involvement in dual-earner couples? The principle of time availability might apply. If fathers care for preschool children while mothers work, they have ample opportunities to engage in playful interaction and to parent authoritatively. However, the time availability argument may not account for involvement as well as it does for physical care. With the 
exception of some kinds of monitoring, none of the components of involvement are as critical to young children's immediate health and safety as caring activities such as changing diapers and feeding. Therefore, reluctant men could avoid them. In addition, playing with children and expressing love are valued forms of involvement among many contemporary fathers (Townsend, 2002). Men might be expected to make time for them regardless of employment schedules, in which case shift work would have little impact.

The existing studies provide little support for the claim that shift work increases positive paternal engagement, but they are few in number. The authors of one study employing time use data (Wight et al., 2008) found no impact of shift work on the amount of time parents spent doing interactive activities (as opposed to routine care) with children of diverse ages. Similarly, fathers caring for children in the evening while their partners were employed did more child care than other men in a recent Canadian study (Rapoport \& Bourdais, 2008), but the frequency of leisure activities with children was actually found to decrease. In a highly nuanced report on the effects of U.S. parents' nonstandard schedules, Presser found that any given shift tended to increase father's involvement in some specific activities while reducing participation in others (2003). For example, she reported that fathers who worked in the evening were less likely than others to eat dinner with their children, but slightly more likely to eat breakfast.

There is even less evidence about warmth and about control. In qualitative studies of couples with a shift worker, parents cited a close-father-child relationship as a benefit of their arrangement (Hattery, 2001; Pagnan et al., 2011). In addition, Davis, Crouter, \& McHale (2006) found that fathers who worked nonstandard schedules knew more about adolescents' whereabouts than men with standard hours did. It seems clear that more needs to be known about paternal engagement, warmth, and control when parents engage in shift work. 


\section{The Present Study}

The existing research on shift work and fathering has other gaps as well. Much of the literature examines the impact of one parent's schedule, even though parents' joint schedules are the true phenomenon of interest. (One would expect the effect of a parent's evening employment to depend on whether the other parent also works in the evening, during the day, or not at all.) Similarly, all nonstandard schedules are frequently combined, making it difficult to know whether the impact of evening work differs from that of other arrangements. Most of the research employs cross-sectional data, and cannot control for prior involvement. This study examines the impact of shift work on care and several aspects of positive involvement among parents of young children, uses measures of joint shift schedules that distinguish between evening and other types of nonstandard work, and employs three waves of longitudinal data that permit controls for prior levels of the dependent variables.

The following hypotheses about the relationship between nonstandard employment and fathering emerge from the literature.

(1) Either parent's nonstandard schedule will increase father care in dual-earner families, compared to couples who are both employed during the day.

(2) Given the present state of knowledge, there are two possibilities concerning fathers' involvement (positive engagement, warmth, and control) in dual-earner families.

(a) Either parent's nonstandard schedule will increase involvement, compared to couples who are both employed during the day.

(b) Parental nonstandard schedules will not be associated with involvement.

(3) The effects of nonstandard employment will be strongest if the mother works in the evening, and the father works during the day. This is because the need for parental 
care is arguably most widespread in the evenings, when children are awake but most paid care is unavailable.

The models that test these hypotheses will control for factors known to be associated with selection into shift work through constraint and by choice (Alterman et al., 2013; Enchautegui, 2013; La Valle et al., 2002; Presser, 2003; Wight et al., 2008). Measures of labour market advantage and disadvantage include the father's race, parents' ages, parents' education levels, parents' marital status, recent receipt of public support, and the number of children in the home. A final selection variable is a lagged measure of the importance the father reports placing on his involvement with his children. The models also control for additional factors known to predict levels of father care or involvement (Parke, 2002; Pleck \& Masciadrelli, 2004), including a prior measure of the outcome variable (when available), the number of hours the child spends in non-parental care, the child's gender, the child's age, whether each parent has long employment hours, whether the child has special needs, and a measure of relationship conflict at the previous interview when available.

\section{Data and Method}

\section{Data Source}

The analysis utilizes restricted-use data from the first three waves of the ECLS-B, a sample of all children born in the U.S. in 2001 that is nationally representative with the application of appropriate weights. ECLS-B, which has been conducted by the U.S. Department of Education's National Center for Education Statistics (NCES), was designed to facilitate longitudinal studies of children's early development and school readiness. The first data collection occurred at nine months, and it was followed by additional rounds at about 24 months and four years of age (the "preschool" observation). The components of this multimethod, multiple-respondent data collection effort that are used here include computer- 
assisted personal interviews with the child's primary parent (usually the mother), and selfadministered surveys filled out by resident fathers when present. ${ }^{1}$ (For a full description of the data, see Snow et al., 2007.)

For the purpose of this study, the sample is restricted to families containing a target child and the same two, opposite-sex, biological or adoptive parents at all three interviews. Out of the original sample of $10,700,8,950$ target children remained in the study through the third wave. ${ }^{2} 5,950$ had the same opposite-sex parents throughout. In about 2,300 of these families, one parent (usually the father) declined to participate in one or more survey waves, which cuts the sample down to 3,650 .

\section{Father Care and Involvement}

Two measures of fathers' care for their children are studied here. The first is the response to the question, "In the past month, how often have you looked after your child while your spouse/partner did other things?" There were five response choices, but because most fathers reported caring for their children at least a few times in the month before the survey, the measure has been recoded into three: every day or almost every day, a few times a week, and a few times a month or less.

The other measure of care is frequency of providing care. This is a latent variable that comes from a battery of questions that asked men to report how often they did specific activities with (or for) the target child on a six-point scale ranging from "more than once a day" to "not at all". The list of activities changed from wave to wave in order to remain age-

1 Because no resident father questionnaire was fielded during the fourth and final wave of the ECLS-

$\mathrm{B}$, only the first three waves are used in the analysis.

2 In keeping with the National Center for Educational Statistics' confidentiality requirements, all sample sizes are rounded to the nearest 50 . 
appropriate. For example, fathers were asked how frequently they "dress" their nine-monthold, and how frequently they "help" a four-year-old "dress him/herself”. Exploratory factor analysis indicated that several items had high loadings on a single factor that could be characterized as "care". Confirmatory factor analysis across waves showed a good fit to the data. The latent factor indicators, their standardized loadings, and fit statistics are listed in Table 1.

(Table 1)

The same series of questions also included items about playing with children. These have been used to create a latent measure of positive engagement. The items once again vary from wave to wave: for example, "play peek-a-boo" at nine months and "play together with toys for building things" at age four. ${ }^{3}$ Table 1 reports a good fit to the data in a confirmatory factor model.

Warmth is a single item, available in the 24-month and preschool data but not the 9month data, asking fathers to assess this statement: "I express my affection by hugging and kissing my children." Fathers originally rated themselves on a five-point scale ranging from "exactly like me" to "not at all like me". For this study, the measure has been dichotomized so that the majority at each wave, who chose "exactly like me", are distinguished from those who chose any other answer.

Participation in decisions is measured by items asking fathers to rate whether they had no, some, or great deal of influence on decisions affecting the child. Each variable was

3 Only two items ("play with toys for building things" and "take outside for a walk or to play") were asked on the age four questionnaire. Although classical factor analysis requires three indicators per factor, the model is identified because more than three items were available at nine and at 24 months. 
dichotomized to indicate whether the father reported a great deal of influence. In the first survey, the only decision asked about was what kind of child care to use (or alternatively, the choice to use no child care). In the second and third waves, fathers were asked about several different decisions, which are treated as indicators of latent decision influence. As shown in Table 1, confirmatory factor analysis once again indicates a good fit to the data.

\section{Joint Employment Schedule}

Parents' joint employment schedule is derived by cross-classifying mothers' reports of their and their spouses' or partners' usual hours. This focus on joint work schedules marks an advance relative to studies that examine only one parent's schedule (usually the mother). In each survey wave, mothers were asked if they and their partner were employed, and if so, whether each usually worked a day, evening, night, rotating, split, or other kind of shift. Among dual-earner couples, there were $36(6 \times 6)$ possible joint shift combinations, but many of them were rare. In addition, the literature has identified evening employment as consequential for parent-child interaction, but has not provided such a strong justification for separately analysing every other type of nonstandard schedule. For these reasons, all nonstandard hours other than evening shifts were grouped together. This resulted in six categories of dual-earner couples:

(1) both parents work during the day;

(2) father day plus mother evening;

(3) father evening plus mother day;

(4) father day plus mother other nonstandard (not evening),

(5) father other nonstandard plus mother day;

(6) both parents work nonstandard shifts (evening or other). 
In the models, dual-earner couples who each work during the day are the omitted category. Other families, who are not the focus of the study, were combined into three broad groups: couples with sole-earning fathers, with sole-earning mothers, and with no earners.

\section{Covariates}

A number of covariates are included in the model due to their known correlations with selection into shift work, as discussed earlier. The first of these is the father's race (four dummy variables, with non-Hispanic white omitted). This is taken from the initial nine month interview with the mother, supplemented by the child's birth certificate if the mother did not provide a valid answer. Time-varying measures of the child's exact age in months, the parents' marital status, and the number of other children living in the household are also drawn from the mother questionnaire. So is a dummy indicator for receipt of government support in the form of Temporary Assistance to Needy Families (TANF), Medicaid, or Food Stamps since the child's birth (during the initial interview) or since the previous interview. Each parent's self-reported educational attainment is taken from the nine month interview. ${ }^{4}$ This is operationalized as separate dummy variables for some college and for college graduation or higher; a high school diploma or less is the omitted category.

One other covariate included to control for selection into shift work by choice is the father's self-reported views about the importance of his involvement. During the baseline interview, respondents were asked to express their level of agreement, on a four-point scale, with seven statements about fathers' roles. In an explanatory factor analysis, five of these items hung together, namely that it is "essential" for fathers to play with their children, that fathers should be "as heavily involved" with children as mothers, that fathers have "long-

\footnotetext{
${ }^{4}$ The results are robust to the use of constant or time-varying attainment.
} 
term effects" on their children, that supporting their mother is "one of the most important things" a father can do for his children, and that fatherhood is "highly rewarding". These have been combined into an index; Cronbach's alpha is .60. Although this index is intended as a measure of selection into shift work, it is possible that the experience of shift work itself changes men's attitudes towards involvement. To avoid this possibility, the variable has been excluded from models predicting nine-month outcomes.

Additional covariates provided by the mother include the father's age, the child's gender, whether each parent is employed for 45 or more hours per week, and the number of hours the child spends in non-parental care. The latter is divided into indicators for low (1-20 hours), medium (21-40) and high (41 or more), with no non-parental care as the omitted category. Mothers also reported whether the child has any special needs from an extensive list that varied from interview to interview. An indicator has been created and set equal to one if mothers reported any special need aside from allergies.

Finally, at each wave mothers answered identical questions about how frequently, on a four-point scale ranging from "often" to "never", they argue with their partner about ten different matters ranging from chores to sex to in-laws. These ten items have been combined into an index. Cronbach's alpha is greater than .80 at each wave, indicating good internal reliability. Lagged conflict is included as a control in models predicting outcomes at 24 months and at age four. In other words, reported conflict at nine months is used to predict care, play, and so on at 24 months, and conflict at 24 months is used to predict father care and involvement at age four. Once again, use of the lagged measure avoids the possibility that conflict influences couples' work schedules, rather than the other way around.

\section{Method}

All models have been estimated in Mplus 7 (Muthén \& Muthén, 2012). The hypotheses are tested using ordinary least squares, logistic, or ordered logistic regression, depending on the 
outcome. The models for care, for play, and for decision influence (aside from nine-month decision influence) take advantage of multiple measures, treating them as observed indicators of latent constructs. In other words, the relevant models have both structural and measurement components.

In addition, for outcomes when children are 24 months old or four years old (the preschool observation), the lagged (prior wave) measure of the dependent variable is included as a covariate. Compared to cross-sectional models, lagged dependent variable models produce superior estimates of the effects of employment schedules on father care and involvement by controlling for prior levels of the outcome (Johnson, 2005). At the initial (nine month) observation, however, there is no lagged outcome to include.

Because a large percentage of cases suffered from missing responses to individual items, multiple imputation was used. The ice add-on for STATA (Royston, 2004) created ten separate data sets with missing values imputed under the MAR (missing at random) assumption. When estimating the structural equation models, Mplus combined these data sets and appropriately adjusted the standard errors. Models run on the sample of cases with complete data (not shown) produce results that are very similar to those presented here.

Model results are adjusted using a sampling weight that corrects for the study's complex sampling design, for attrition from the survey, and for father non-participation among families in which the mother and child participated (Wheeless, Ault, \& Park, 2008). However, the predicted effects of parents' joint employment schedules, which are the main coefficients of interest, may still be biased if non-response varies by schedule type. To assess the extent of the problem, joint shift schedules among families included and excluded from the analysis were compared. Dual-earner couples with one or two nonstandard workers were slightly more likely to be excluded than dual-earner couples who both work during the day (results not shown). The difference is five percentage points at the first two waves, and two 
percentage points at the third. It is therefore possible that the results are affected by slightly greater selectivity among couples with a nonstandard worker.

\section{Results}

Table 2 contains weighted means or proportions for all study variables. ${ }^{5}$ With one exception, all measures of father care and involvement decline or remain unchanged as children grow. However, the indicators of latent care, play, and decision influence vary from wave to wave, so it cannot be assumed that this represents a true decline in the underlying behaviors, as opposed to an artefact of the questions asked.

(Table 2)

At each wave, the largest group in the study is the heterogeneous category of families with a sole-earning father, regardless of his work schedule. Among dual-earner families, those who are both employed during the day dominate. Although some groups of nonstandard dual-earner couples are small in proportional terms, there are at least 85 unweighted cases in every cell. The proportions in each category are fairly stable from wave to wave, but they mask a good deal of circulation, particularly in and out of nonstandard dual-earner arrangements. Between the nine-month and 24-month surveys, only 50 percent of nonstandard dual-earner couples stay in any type of nonstandard dual-earner schedule. Between the 24-month and preschool surveys, the corresponding figure is 52 percent.

The remainder of the table presents means and proportions for the covariates. The largest group of fathers are non-Hispanic white, with Hispanic as the second most common

\footnotetext{
${ }^{5}$ Because of the way that the latent outcome variables are scaled, the variable means are not readily comparable across waves. Instead, the means of indexes calculated using the latent variable indicators are reported.
} 
category. Although parents do not have to be married to be included in the analysis, they must live together at all three observations, so it is logical that a large percentage of them are married at the initial observation, and that the number grows still higher over time. Similarly, it is not surprising that the average number of other children in the household increases from 1.04 to 1.48 over time, reflecting the arrival of later-born children.

Mothers and fathers are equally educated on average. Receipt of benefits from TANF, Medicaid, or Food Stamps is fairly stable across interviews. Fathers tend to endorse the importance of involvement very strongly, with a mean score of 3.65 on a scale that ranges from 1 to 4 .

Target children are equally split between boys and girls. Compared to mothers, it is not surprising that fathers are much more likely to be employed for 45 hours or longer. It is worth noting that a majority of target children have no non-parental care at nine or 24 months. When they are four years old on average, most have made the transition to an outof-home setting, which is typically preschool. This can be expected to restrict the need for father care and involvement during the daytime hours.

The fraction of children whose mothers report a special need is fairly stable from wave to wave, although it is a little higher at 24 months because of children with delays in speech at that time. Finally, the frequency of marital conflict is reported to grow from the nine month to the 24 month observations.

\section{Structural model results}

\section{Solo Care}

The estimated effects of nonstandard dual-earner employment on father care and involvement, as compared to a standard daytime dual-earner schedule, are reported in Table

3. Coefficients were estimated for families with one or no earners, but they are not shown 
because these families are not the substantive focus of the investigation. Nor are the effects of the lagged outcome measure or of the controls shown. Interested readers may see the online supplementary file for full model results.

(Table 3)

The results show there are significant, positive effects of shift work on the amount of solo father care in dual-earner families. This is particularly true at the 24 month and the preschool observations. The combination of a father who works during the day and a mother who works during the evening predicts high solo care at 24 months $(\beta=.35)$ and at the preschool observation $(\beta=.69)$, but not at nine months. So does the combination of a father who works an "other" nonstandard shift than an evening schedule and a partner employed during the day ( $\beta=.23$ at 24 months and $\beta=.32$ at the preschool observation). The same is true when couples both work nonstandard hours $(\beta=.32$ and .47 , respectively).

By contrast, the father evening + mother day combination is significant at nine months $(\beta=.64)$ and at the preschool survey $(\beta=.53)$, but not at 24 months. Finally, when the father works during the day and the mother works an "other" shift, the father's solo care does not differ from that of a man in a couple who each work during the day.

Not only are many effects of work schedules significant, but they are also large. Inspection of Table A1 in the supplementary file shows that at the nine month interview, being in a couple with a father evening + mother day employment schedule has the largest standardized effect on solo care. At 24 months, the beta for the father day + mother evening combination is the third largest. At age four, the effect sizes for the father day + mother evening, the father evening + mother day, and the both nonstandard combinations are the second, third, and fourth largest, respectively. 


\section{Care Frequency}

Nonstandard schedules are also related to the frequency of total father care, but in fewer circumstances. When children are nine months old, fathers are predicted to provide care more frequently in father evening + mother day couples $(\beta=1.03)$ and when both parents have nonstandard schedules $(\beta=.47)$ than in couples who both work during the day. These are among the largest effect sizes in the results, as can be seen in Table A2 in the supplement. At 24 months, however, there are no statistically significant effects of non-standard work schedules. At the preschool observation, the combination of a father who works during the day and a mother who works during the evening is associated with frequent care $(\beta=.32)$, as is an arrangement where both parents have nonstandard schedules $(\beta=.23)$. At all three observations, couples in which one parent works during the day and the other parent works an "other" nonstandard shift are the same as couples who both have day shifts.

\section{Play Frequency}

At the nine-month observation, fathers who work during the evening, and whose partners work during the day, are predicted to play more frequently than their counterparts in dualearner couples who each work during the day. This effect $(\beta=.27)$ is significant, but it is not one of the largest ones in the full model (Table A3). At 24 months, nonstandard parental work schedules are not associated with the frequency with which fathers report playing with their children. The same is true when children are age four, although the effect for the father "other" shift + mother day combination falls just short of statistical significance $(\beta=0.26, p$ $=.051)$. Considering that only two of fifteen coefficients reach or approach significance, the results suggest that nonstandard employment does not play a major role in shaping how frequently fathers play with their young children. This is consistent with hypothesis $2 b$, which predicted that shift work would not affect father involvement, as opposed to father 
care.

\section{Warmth}

At 24 months and at age four, no nonstandard work schedule combinations are associated with the frequency with which fathers report expressing warmth and affection to their young children. (Recall that this measure was not collected at the nine month observation.) This, too, is consistent with hypothesis $2 b$.

\section{Decision influence}

Nonstandard work arrangements are not predicted to affect fathers' involvement in important decisions about the child in dual-earner families. This is true at all three time points. Thus, the results from decision influence also support hypothesis $2 b$.

\section{Discussion}

This study has contributed to our understanding of when and how fathering is affected by nonstandard and non-overlapping employment in dual-earner couples with young children. First, the results for the two measures of care largely support hypothesis 1 . Nonstandard joint schedules frequently predict greater solo care by fathers, when compared with couples in which both partners work during daytime hours. More specifically, eight out of fifteen regression coefficients are significant at the.05 alpha level or better. Employment schedules also predict more frequent care overall, but less consistently.

In contrast, there is only one significant effect on one of the measures of positive involvement used in this study (play), with a second falling just short of significance. There are no effects of shift work on warmth or decision influence in dual-earner families. The results support hypothesis $2 \mathrm{~b}$ much more than $2 \mathrm{a}$. To put it succinctly, employment scheduling mainly appears to shape the context in which involvement takes place in dual- 
earner families. Shift work by one or both parents increases the amount of time fathers and their young children spend together in the mother's absence, as the principle of time availability would lead one to expect. Conversely, it rarely affects the frequency or likelihood of involvement apart from care. This pattern of findings resembles those in comparable studies by Rapoport \& Le Bourdais (2008) and by Wight, Raley, and Bianchi (2008).

At the same time, this study has extended and enriched past research by distinguishing among joint employment schedules and among child ages. The expectation, as stated in the form of hypothesis 3 , was that the father day + mother evening combination would have the greatest impact. This family type is associated with fathers' solo care at 24 months and at age four, and with greater paternal care overall at age four. It is not associated with care at nine months, but it must be remembered that the models for outcomes when children are nine months old are less well specified, primarily because there is no lagged outcome to control. In short, the evidence shows that, after controlling for the extent of father care at an earlier time point, fathers are highly involved in care when they have day shifts and their wives have evening shifts.

However, this is not true only of the father day + mother evening schedule. It is also the case that fathers are predicted to do a good deal of solo care in couples with a father "other" shift + mother day arrangement, as well as when neither parent works during the day. Moreover, fathers are predicted to provide their four-year-old children with a large amount of total care when both they and their wives work non-day shifts. As a result, hypothesis 3 is partially supported. Elevated levels of father care are characteristic of the father day + mother evening arrangement, but not only of this joint schedule combination.

A surprising pattern in the results is revealed by comparing the three time points. Although nonstandard schedules predict more solo care by fathers at every observation, they 
only predict more frequent total care at nine months and at age four. It is tempting to ask whether couples with nonstandard joint schedules when their children are two years old differ somehow from their counterparts with nine-month-olds and four-year olds. Additional analysis revealed that men reported feeling significantly more stressed about parenting $(p<$ $.001)$ when they were in nonstandard dual-earner couples at the 24-month observation but not at the nine-month interview, compared to men in non-standard dual-earner couples at both time points (result not shown). It is possible to speculate that feelings of stress about sharing care hinder these men's involvement with their children. Similarly, it may be important that a large proportion of sample children made a transition to out-of-home preschool between the second observation and the last, reducing the need for parental care during the daytime. It is consistent with older research (Glass, 1998) that fathers are more likely to provide care when the total amount of care needed is smaller.

In the final analysis, however, one must be cautious not to read too much into the sparse results for care frequency, play, warmth, and decision influence. The clearest finding here is that non-standard joint parental schedules increase fathers' solo care more than any of these other phenomena. One possible way to interpret these results is in light of the power of traditional gendered norms. Young children cannot care for themselves, so fathers in couples with non-overlapping shifts may be constrained to watch them while their partners are on the job. In keeping with socially-structured preferences, however, fathers may avoid high involvement even when they share care.

While it is likely that the above speculation holds true about some specific families, several small-scale interview studies of families with non-overlapping shifts (Hattery, 2001; Pagnan et al., 2011) have painted a very different picture. The authors of these studies have described fathers who are highly involved in parenting, and who have close relationships with their children to show for it. The findings of the present study can best be reconciled 
with this literature by relying on the insight that some forms of paternal involvement, such as play and expressing warmth, are quite normative for fathers and are not necessarily timeintensive. If this is true, then barring extreme circumstances, fathers can honestly report doing them frequently regardless of their and their partners' work schedules.

The above discussion, however, remains conjecture. Future quantitative research should more fully test whether any kinds of paternal involvement are affected by shift work. Researchers should gather data about forms of father involvement (as opposed to care) that might be expected, on the basis of theory and observational research, to be especially affected by non-overlapping parental employment.

In addition to the unavailability of desired measures of involvement, the limitations of the ECLS-B data employed here include the fact that measures of paternal care and involvement, along with many of the covariates, are drawn from a single source (the father himself). This introduces a risk of biased coefficient estimates (Amato, 1998). Some of these measures - solo care, warmth, and decision involvement at nine months - are single items, which means they are likely to be measured less reliably than latent variables with multiple indicators. In addition, the data source is lacking information about prior parenting in the data from the survey's initial wave, as already mentioned. Therefore, the estimated effects of employment scheduling are not as trustworthy as they are for the two subsequent observations.

Another limitation of the study is that although the regression models control for factors known to predict selection into shift work through choice and through constraint, one cannot rule out selection effects in a non-experimental study like this one. It was particularly difficult, given the measures available in ECLS-B, to control for a preference for nonoverlapping schedules among couples with young children. Therefore, the possibility 
remains that the positive effects of shift work on fathering outcomes - particularly solo care might actually be due to voluntary selection into nonstandard schedules.

Finally, the sample is composed only of households in which children lived with the same biological or adoptive parents at each wave. It would be valuable to study the impact of shift work on care and involvement in other family structures, such as those containing a stepfather or a single father.

In spite of the inevitable limitations, this study has made an important contribution by examining the impact of both parents' employment schedules on father involvement with young children in a nationally-representative, longitudinal sample. In light of the fact that shift work is often identified as a risk factor for children, scholars should next ask whether fathers can mitigate the impact of either parent's nonstandard employment on children in dual-earner families in families where they do become highly involved parents.

For policymakers and family service practitioners, this analysis underscores the need to support fathers of young children who work different shifts than their partners. Father involvement has a well-established influence on positive child outcomes. Efforts should be made to support involvement among men who are home alone with their young children, perhaps by teaching skills and by communicating the value of engagement.

\section{Acknowledgements}

The author wishes to thank Emily Rosenbaum, Christopher Morett, Jennifer Hook, Kei Nomaguchi, and Rebecca Glauber for their valuable feedback on earlier drafts of this article.

\section{Notes on contributor}

Matthew Weinshenker is an Associate Professor of Sociology at Fordham University in Bronx, NY. His research focuses on fatherhood and on work-family issues in the contemporary United States. 


\section{References}

Alterman, T., Luckhaupt, S. E., Dahlhamer, J. M., Ward, B. W., \& Calvert, G. M. (2013). Prevalence Rates of Work Organization Characteristics Among Workers in the U.S.: Data From the 2010 National Health Interview Survey. American Journal of Industrial Medicine, 56, 647-659.

Bellavia, G., \& Frone, M. R. (2004). Work-family Conflict. In J. Barling, E. K. Kelloway \& M. R. Frone (Eds.), Handbook of Work Stress. Thousand Oaks, CA: Russell Sage.

Brayfield, A. (1995). Juggling Jobs and Kids: The Impact of Employment Schedules on Fathers' Caring for Children. Journal of Marriage and Family, 57, 321-332.

Bronfenbrenner, U. (1994). Ecological Models of Human Development. In T. N. P. T. Husen (Ed.), International Encyclopedia of Education. Oxford, UK: Pergamon Press.

Coverman, S. (1983). Gender, Domestic Labor Time, and Wage Inequality. American Sociological Review, 48, 623-637.

Davis, K. D., Crouter, A. C., \& McHale, S. M. (2006). Implications of Shift Work for ParentAdolescent Relationships in Dual-earner Families. Family Relations, 55, 450-460.

Enchautegui, M. E. (2013). Nonstandard Work Schedules and the Well-being of Low-income Families. Washington, DC: Urban Institute.

Fox, L., Han, W.-J., Ruhm, C., \& Waldfogel, J. (2013). Time for Children: Trends in the Employment Patterns of Parents 1967-2009. Demography, 50, 25-49.

Glass, J. (1998). Gender Liberation, Economic Squeeze, or Fear of Strangers: Why Fathers Provide Infant Care in Dual-Earner Families. Journal of Marriage and Family, 60, 821-834. 
Grzywacz, J. G., Daniel, S. S., Tucker, J., Walls, J., \& Leerkes, E. (2011). Nonstandard Work Schedules and Developmentally Generative Parenting Practices: An Application of Propensity Score Techniques. Family Relations, 60, 45-59.

Han, W.-J. (2005). Maternal Nonstandard Work Schedules and Child Cognitive Outcomes. Child Development, 76, 137-154.

Han, W.-J. (2008). Shift Work and Child Behavioral Outcomes. Work, Employment, and Society, 22, 67-87.

Hattery, A. J. (2001). Tag-Team Parenting: Costs and Benefits of Utilizing Nonoverlapping Shift Work in Families With Young Children. Families in Society: The Journal of Contemporary Human Services, 82, 419-427.

Heyman, J. (2000). The Widening Gap: Why America's Working Families Are in Jeopardy and What Can Be Done About It. New York: Basic Books.

Johnson, D. (2005). Two-Wave Panel Analysis: Comparing Statistical Methods for Studying the Effects of Transitions. Journal of Marriage and Family, 67, 1061-1075.

Joshi, P., \& Bogen, K. (2007). Nonstandard Schedules and Young Children's Behavioral Outcomes Among Working Low-Income Families. Journal of Marriage and Family, 69, 139-156.

La Valle, I., Arthur, S., Millward, C., Scott, J., \& Clayden, M. (2002). Happy Families? Atypical Work and Its Impact on Family Life. Bristol, UK: Policy Press.

Muthén, L. K., \& Muthén, B. O. (2012). Mplus User's Guide. Seventh Edition. Los Angeles, CA: Muthén \& Muthén. 
Pagnan, C. E., Lero, D. S., \& Wadsworth, S. M. M. (2011). It doesn't always add up: Examining dual-earner couples' decision to off-shift. Community, Work, \& Family, 14, 297-316.

Parke, R. D. (2002). Fathers and Families. In M. H. Bornstein (Ed.), Handbook of Parenting Volume 3: Being and Becoming a Parent (pp. 27-73). Mahwah, NJ: Lawrence Erlbaum Associates.

Pleck, J. H. (2007). Why Could Father Involvement Benefit Children? Theoretical Perspectives. Applied Developmental Science, 11, 196-202.

Pleck, J. H. (2010). Paternal Involvement: Revised Conceptualization and Theoretical Linkages with Child Outcomes. In M. E. Lamb (Ed.), The Role of the Father in Child Development (5th ed., pp. 58-85). Hoboken, NJ: John Wiley \& Sons.

Pleck, J. H., \& Masciadrelli, B. P. (2004). Paternal Involvement by U.S. Resident Fathers: Levels, Sources, and Consequences. In M. E. Lamb (Ed.), The Role of the Father in Child Development (4th ed.) (4th ed., pp. 222-271). Hoboken, NJ: John Wiley \& Sons.

Presser, H. B. (2003). Working in a 24/7 Economy: Challenges for America's Families. New York: Russell Sage.

Rapoport, B., \& Bourdais, C. L. (2008). Parental Time and Working Schedules. Journal of Population Economics(21), 903-932.

Rosenbaum, E., \& Morett, C. R. (2009). The Effect of Parents' Joint Work Schedules on Infants' Behavior Over the First Two Years of Life: Evidence from the ECLSB. Maternal and Child Health Journal, 13, 732-744. 
Royston, P. (2004). Multiple Imputation of Missing Values. Stata Journal, 4, 227-241.

Snow, K., Thalji, L., Derecho, A., Wheeless, S., Lennon, J., Kinsey, S., . . Park, J. (2007). Early Childhood Longitudinal Study, Birth Cohort (ECLS-B): Preschool Year Data File User's Manual (2005-06) (NCES 2008-024). Washington, DC: National Center for Education Statistics, Institute of Education Sciences, U.S. Department of Education.

Strazdins, L., Clements, M. S., Korda, R. J., Broom, D. H., \& D'Souza, R. M. (2006). Unsociable Work? Nonstandard Work Schedules, Family Relationships, and Children's Well-Being. Journal of Marriage and Family, 68, 394-410.

Townsend, N. W. (2002). The Package Deal: Marriage, Work, and Fatherhood in Men's Lives. Philadelphia: Temple University Press.

Wheeless, S., Ault, K., \& Park, J. (2008). Early Childhood Longitudinal Study, Birth Cohort (ECLS-B), Methodology Report for the Preschool Data Collection (2005-06), Volume II: Sampling. Washington, DC: National Center for Education Statistics, Institute of Education Sciences, U.S. Department of Education.

Wight, V. R., Raley, S. B., \& Bianchi, S. M. (2008). Time for Children, One's Spouse and Oneself among Parents Who Work Nonstandard Hours. Social Forces, 87, 243-271. 
Table 1.

Confirmatory factor analyses of latent outcome variables $(\mathrm{N}=3,650)$

\begin{tabular}{|c|c|c|c|c|c|}
\hline Care & & & & & \\
\hline Nine-month survey: & & 24-month survey: & & Preschool survey & \\
\hline Change diaper & 0.84 & $\begin{array}{l}\text { Change diapers/ } \\
\text { help use toilet }\end{array}$ & 0.82 & Prepare meals & 0.71 \\
\hline $\begin{array}{l}\text { Prepare } \\
\text { meals/bottles }\end{array}$ & 0.89 & Prepare meals & 0.72 & Help to bed & 0.68 \\
\hline $\begin{array}{l}\text { Feed child/give } \\
\text { child bottle }\end{array}$ & 0.89 & Help to bed & 0.65 & Help bathe & 0.80 \\
\hline Put to sleep & 0.66 & Give bath & 0.74 & Help dress self & 0.78 \\
\hline Wash/bathe & 0.69 & Help get dressed & 0.82 & Help brush teeth & 0.77 \\
\hline Dress & 0.79 & Help brush teeth & 0.63 & $\begin{array}{l}\chi^{2}(116)=1405.5 \\
R M S E A=.055\end{array}$ & $<.001$ \\
\hline
\end{tabular}

Play

Nine-month survey:

24-month survey:

Preschool survey:

Play peek-a-boo with your child

0.67 Play chasing games

0.66

Play with toys for

0.67 building things

Hold him/her ${ }^{\mathrm{a}}$

0.81 Take for ride on

0.66 Take outside for a

0.65

shoulders or back walk or to play

Tickle child, blow on belly, or move

0.85 Play with games or 0.78

limbs around ${ }^{\mathrm{a}}$

toys indoors ${ }^{\mathrm{b}}$

Take outside for a

$0.60 \quad \chi^{2}(24)=299.70, p<.001$

walk or to play ${ }^{\mathrm{b}}$

RMSEA $=.056$

Decision influence

Nine-month survey:

24-month survey:

Preschool survey:

\begin{tabular}{|c|c|c|c|c|}
\hline \multirow[t]{5}{*}{$\mathrm{c}$} & Discipline & 0.72 & Discipline & 0.73 \\
\hline & Nutrition & 0.81 & Nutrition & 0.85 \\
\hline & Health care & 0.90 & Health care & 0.90 \\
\hline & Child care & 0.88 & Child care & 0.76 \\
\hline & & & $\begin{array}{l}\chi^{2}(19)=15 \\
R M S E A=.\end{array}$ & .001 \\
\hline
\end{tabular}

"Recoded from six categories to four because very few fathers reported "not at all" or "rarely"

${ }^{b}$ Recoded from six categories to five because very few fathers reported "not at all"

${ }^{\mathrm{c}}$ Not modelled as a latent variable because only one question (child care) was asked. 
Table 2.

Weighted means or proportions for variables $(\mathrm{N}=3,650)$

\begin{tabular}{llll}
\hline Variables & Nine-month & 24-month & Preschool \\
\hline Solo care (1-3) & 2.23 & 2.10 & 2.09 \\
Care frequency $^{\mathrm{a}}(1-6)$ & 4.53 & 4.31 & 4.01 \\
Play frequency $^{\mathrm{a}}(1-6)$ & 5.48 & 4.48 & 3.81 \\
Warmth & - & 0.72 & 0.62 \\
Decision influence & 0.74 & 0.60 & 0.62 \\
Joint employment schedule & & & \\
$\quad$ Both day (reference) & 0.30 & 0.31 & 0.32 \\
Father day + mother evening & 0.04 & 0.04 & 0.04 \\
Father evening + mother day & 0.02 & 0.03 & 0.03 \\
Father day + mother "other" shift & 0.06 & 0.05 & 0.07 \\
Father "other" shift + mother day & 0.04 & 0.05 & 0.06 \\
Both nonstandard (evening or other) & 0.03 & 0.03 & 0.03 \\
Sole-earning father & 0.44 & 0.44 & 0.41 \\
Sole-earning mother & 0.03 & 0.04 & 0.02 \\
No earners & 0.03 & 0.02 & 0.02
\end{tabular}

Father race

Non-Hispanic white (reference) $\quad 0.66$

Non-Hispanic black $\quad 0.06$

Hispanic $\quad 0.22$

Asian/Pacific Islander $\quad 0.04$

Other $\quad 0.02$

Child age (months) $\quad 10.25$

$24.26 \quad 52.11$

Married $\quad 0.88$

$0.90 \quad 0.93$

$\begin{array}{llll}\text { Number of other children in household } & 1.04 & 1.17 & 1.48\end{array}$

Mother education

High school or less (reference) $\quad 0.38$

Some college $\quad 0.28$

$\begin{array}{ll}\text { College graduate or more } & 0.34\end{array}$

Father education

High school or less (reference) $\quad 0.40$

Some college $\quad 0.27$

$\begin{array}{ll}\text { College graduate or more } & 0.33\end{array}$ 


\begin{tabular}{llll}
\hline Receipt of government support & 0.25 & 0.21 & 0.24 \\
Support for father involvement (1-4) & 3.65 & & \\
Father age (years) & 32.43 & 33.57 & 35.51 \\
Child female & 0.48 & & \\
Mother employed 45+ hours & 0.04 & 0.04 & 0.06 \\
Father employed 45+ hours & 0.36 & 0.37 & 0.40 \\
Hours in non-parental care & & & \\
$\quad$ None (reference) & 0.56 & 0.56 & 0.22 \\
$\quad 0.16$ & 0.14 & 0.39 \\
$\quad$ Low (1-20) & 0.19 & 0.22 & 0.29 \\
$\quad$ High (41+) & 0.09 & 0.08 & 0.10 \\
Child has special needs & 0.07 & 0.09 & 0.07 \\
Relationship conflict at prior observation & - & 1.79 & 1.90 \\
(1-4) & & & \\
\hline
\end{tabular}

Note: Imputed values are excluded from the calculation of means and proportions in this table.

${ }^{a}$ With the exception of nine-month decision influence, these are the means of indexes calculated using the latent variable indicators. 
Table 3.

Summary of predicted effects of nonstandard dual-earner employment on father care and involvement

\begin{tabular}{|c|c|c|c|}
\hline Variable & $\begin{array}{l}\text { Nine-month } \\
\beta\end{array}$ & $\begin{array}{l}\text { 24-month } \\
\beta\end{array}$ & $\begin{array}{l}\text { Preschool } \\
\beta\end{array}$ \\
\hline \multicolumn{4}{|c|}{ Panel A: Solo care } \\
\hline \multicolumn{4}{|l|}{ Schedule type (vs. both parents day) } \\
\hline Father day + mother evening & 0.28 & $0.35 * *$ & $0.69 * * *$ \\
\hline Father evening + mother day & $0.64 * * *$ & 0.20 & $0.53 * *$ \\
\hline Father day + mother "other" shift & -0.04 & 0.18 & 0.11 \\
\hline Father "other" shift + mother day & 0.14 & $0.23 *$ & $0.33 * *$ \\
\hline Both nonstandard (evening or other) & 0.34 & $0.32 *$ & $0.47 * *$ \\
\hline \multicolumn{4}{|c|}{ Panel B: Care frequency } \\
\hline \multicolumn{4}{|l|}{ Schedule type (vs. both parents day) } \\
\hline Father day + mother evening & 0.20 & 0.15 & $0.32 *$ \\
\hline Father evening + mother day & $1.03 * * *$ & 0.32 & 0.29 \\
\hline Father day + mother "other" shift & -0.03 & -0.11 & 0.08 \\
\hline Father "other" shift + mother day & 0.18 & 0.14 & 0.12 \\
\hline Both nonstandard (evening or other) & $0.47 * * *$ & 0.01 & $0.23 *$ \\
\hline
\end{tabular}

\section{Panel C: Play frequency}

\begin{tabular}{llcc}
\hline $\begin{array}{l}\text { Schedule type (vs. both parents day) } \\
\text { Father day + mother evening }\end{array}$ & 0.17 & 0.11 & 0.02 \\
Father evening + mother day & $0.52^{*}$ & 0.12 & 0.18 \\
Father day + mother "other" shift & 0.05 & -0.01 & 0.07 \\
Father "other" shift + mother day & -0.07 & -0.01 & 0.26 \\
Both nonstandard (evening or other) & -0.12 & -0.07 & 0.13 \\
\hline \multicolumn{2}{c}{ Panel D: Warmth } & & \\
\hline Schedule type (vs. both parents day) & & & 0.01 \\
Father day + mother evening & & -0.06 & 0.07 \\
Father evening + mother day & & 0.07 & -0.03 \\
Father day + mother "other" shift & 0.17 & 0.15 \\
Father "other" shift + mother day & -0.13 & 0.11 \\
Both nonstandard (evening or other) & 0.27 & \\
\hline
\end{tabular}


Table 3. (Cont.)

\section{Panel E: Decision influence}

\begin{tabular}{lccc}
\hline Schedule type (vs. both parents day) & & & \\
Father day + mother evening & 0.17 & 0.02 & 0.22 \\
Father evening + mother day & -0.06 & 0.03 & 0.03 \\
Father day + mother "other" shift & -0.08 & -0.03 & -0.08 \\
Father "other" shift + mother day & 0.05 & 0.09 & 0.09 \\
Both nonstandard (evening or other) & 0.15 & 0.13 & 0.15 \\
\hline
\end{tabular}

Note: $\mathrm{N}=3,650$. All models include a set of indicators for single and no-earner families. Prior levels of the outcome (when available) and sociodemographic variables from Table 2 are controlled.

$* p<.05 . * * p<.01 . * * * p<001$. 
Table A1.

Standardized coefficients for model predicting solo care $(\mathrm{N}=3,650)$

\begin{tabular}{llcc}
\hline Variables & Nine-month & $24-$ month & Preschool \\
\hline Solo care at prior observation & & $0.41^{* * * *}$ & $0.35^{* * *}$ \\
Joint employment schedule (vs. both day) & & & \\
$\quad$ Father day + mother evening & 0.28 & $0.35^{* *}$ & $0.69^{* * *}$ \\
Father evening + mother day & $0.64^{* * *}$ & 0.20 & $0.53^{* *}$ \\
Father day + mother "other" shift & -0.04 & 0.18 & 0.11 \\
Father "other" shift + mother day & 0.14 & $0.23^{*}$ & $0.33^{* *}$ \\
Both nonstandard (evening or other) & 0.34 & $0.32^{*}$ & $0.47^{* *}$ \\
Sole-earning father & $-0.27^{* *}$ & $-0.34^{* * *}$ & $-0.15^{*}$ \\
Sole-earning mother & $0.53^{* * *}$ & $0.68^{* * *}$ & $0.75^{* * *}$ \\
No earners & 0.00 & -0.33 & 0.25
\end{tabular}

Father race (vs. Non-Hispanic white)

Non-Hispanic black

$\begin{array}{lll}0.18 & 0.15 & -0.20 *\end{array}$

Hispanic

$0.32 * * *$

0.07

0.13

Asian/Pacific Islander

$0.32 * * *$

$0.14 *$

0.12

Other

0.03

0.10

0.21

Child age (months)

0.00

0.03

$0.01 * *$

Married

$-0.08$

$-0.06$

$-0.12$

Number of other children in household

0.00

0.05

0.01

Mother education (vs. h.s. or less)

Some college

0.02

0.00

$-0.04$ 
College graduate or more

0.02

$-0.07$

$-0.02$

Father education (vs. h.s. or less)

Some college

0.03

$-0.10$

0.09

College graduate or more

0.09

0.00

0.07

Receipt of government support

0.07

0.06

$-0.03$

Support for father involvement (1-4)

$0.25 * * *$

$0.30 * * *$

Father age (years)

0.01

0.01

0.00

Child female

0.00

$-0.06$

$-0.02$

Mother employed 45+ hours

0.12

$-0.01$

$0.36 * * *$

Father employed $45+$ hours

$-0.19 * * *$

$-0.09$

$-0.27 * * *$

Hours in non-parental care (vs. none)

Low (1-20)

$-0.03$

0.11

$-0.06$

Medium (21-40)

$-0.04$

$-0.09$

$-0.09$

High (41+)

$-0.10$

0.15

$-0.02$

Child has special needs

$-0.20$

0.01

$-0.06$

Relationship conflict at prior observation (1-4)

$\mathrm{R}^{2}$

0.09

0.02

$-0.01$

$* p<.05 ; * * p<.01 ; * * * p<.001$ 
Table A2

Standardized coefficients for model predicting care frequency $(\mathrm{N}=3,650)$

\begin{tabular}{|c|c|c|c|}
\hline \multicolumn{4}{|c|}{ Structural Model } \\
\hline Variables & Nine-month & 24-month & Preschool \\
\hline Care frequency at prior observation & & $0.58 * * *$ & $0.50 * * *$ \\
\hline \multicolumn{4}{|l|}{ Joint employment schedule (vs. both day) } \\
\hline Father day + mother evening & 0.20 & 0.15 & $0.32 *$ \\
\hline Father evening + mother day & $1.03 * * *$ & 0.32 & 0.29 \\
\hline Father day + mother "other" shift & -0.03 & -0.11 & 0.08 \\
\hline Father "other" shift + mother day & 0.18 & 0.14 & 0.12 \\
\hline Both nonstandard (evening or other) & $0.47 * * *$ & 0.01 & $0.23 *$ \\
\hline Sole-earning father & -0.15 & $-0.28 * * *$ & $-0.21 * *$ \\
\hline Sole-earning mother & $0.62 * * *$ & $0.40 * *$ & $0.42 * *$ \\
\hline No earners & 0.21 & -0.05 & 0.19 \\
\hline \multicolumn{4}{|l|}{ Father race (vs. Non-Hispanic white) } \\
\hline Non-Hispanic black & $0.31 * * *$ & 0.15 & -0.09 \\
\hline Hispanic & -0.01 & 0.01 & 0.06 \\
\hline Asian/Pacific Islander & -0.01 & $-0.17 *$ & -0.06 \\
\hline Other & 0.20 & 0.12 & 0.01 \\
\hline Child age (months) & 0.00 & $0.07 * *$ & 0.00 \\
\hline Married & -0.10 & -0.16 & -0.06 \\
\hline Number of other children in household & 0.01 & 0.00 & -0.04 \\
\hline \multicolumn{4}{|l|}{ Mother education (vs. h.s. or less) } \\
\hline Some college & 0.07 & 0.13 & 0.11 \\
\hline College graduate or more & 0.03 & 0.06 & $0.18 *$ \\
\hline \multicolumn{4}{|l|}{ Father education (vs. h.s. or less) } \\
\hline Some college & -0.03 & -0.10 & -0.14 \\
\hline College graduate or more & -0.03 & 0.00 & 0.04 \\
\hline Receipt of government support & 0.02 & 0.06 & -0.01 \\
\hline Support for father involvement (1-4) & & $0.68 * * *$ & $0.50 * * *$ \\
\hline Father age (years) & $-0.01 * *$ & $-0.01 *$ & $-0.01 *$ \\
\hline Child female & $-0.13 * *$ & $-0.14 * *$ & $-0.24 * * *$ \\
\hline
\end{tabular}




\begin{tabular}{lccc}
\hline Mother employed 45+ hours & $0.27^{*}$ & 0.17 & $0.34^{* *}$ \\
Father employed 45+ hours & $-0.27^{* * *}$ & $-0.26^{* * *}$ & $-0.26^{* * *}$ \\
Hours in non-parental care (vs. none) & & & \\
Low (1-20) & $0.37^{* * *}$ & 0.02 & $0.15^{*}$ \\
Medium (21-40) & $0.24^{* *}$ & 0.07 & $0.20^{*}$ \\
High (41+) & 0.18 & 0.12 & 0.18 \\
Child has special needs & 0.05 & -0.04 & -0.05 \\
$\begin{array}{l}\text { Relationship conflict at prior observation }(1- \\
4)\end{array}$ & & $-0.18^{* * *}$ & -0.05 \\
\hline$R^{2}$ & 0.15 & & \\
$\chi^{2}$ & $576.07 * * *$ & $1029.24 * * *$ & $916.49 * * *$ \\
$($ df) & $(149)$ & $(383)$ & $(343)$ \\
RMSEA & 0.03 & 0.02 & 0.02
\end{tabular}

\begin{tabular}{|c|c|c|c|c|c|}
\hline \multicolumn{6}{|c|}{ Measurement Model } \\
\hline \multicolumn{2}{|c|}{ Nine-month survey } & \multicolumn{2}{|l|}{ 24-month } & \multicolumn{2}{|l|}{ Preschool } \\
\hline Change diaper & $0.84 * * *$ & $\begin{array}{l}\text { Change diapers/ } \\
\text { help use toilet }\end{array}$ & $0.84 * * *$ & Prepare meals & $0.69 * * *$ \\
\hline $\begin{array}{l}\text { Prepare } \\
\text { meals/bottles }\end{array}$ & $0.90 * * *$ & Prepare meals & $0.70 * * *$ & Help to bed & $0.72 * * *$ \\
\hline $\begin{array}{l}\text { Feed child/give } \\
\text { child bottle }\end{array}$ & $0.91 * * *$ & Help to bed & $0.69 * * *$ & Help bathe & $0.80 * * *$ \\
\hline Put to sleep & $0.70 * * *$ & Give bath & $0.75 * * *$ & Help dress self & $0.80 * * *$ \\
\hline Wash/bathe & $0.66 * * *$ & Help get dressed & $0.83 * * *$ & Help brush teeth & $0.80 * * *$ \\
\hline Dress & $0.79 * * *$ & Help brush teeth & $0.65 * * *$ & & \\
\hline
\end{tabular}

Note: Measurement model factor loadings are reported when the latent variable is the outcome. Factor loadings are similar when the latent variable is a lagged predictor.

$* p<.05 ; * * p<.01 ; * * * p<.001$ 
Table A3.

Standardized coefficients for model predicting play frequency $(\mathrm{N}=3,650)$

\begin{tabular}{|c|c|c|c|}
\hline \multicolumn{4}{|c|}{ Structural Model } \\
\hline Variables & Nine-month & 24-month & Preschool \\
\hline Play frequency at prior observation & & $0.38 * * *$ & $0.50 * * *$ \\
\hline \multicolumn{4}{|l|}{ Joint employment schedule (vs. both day) } \\
\hline Father day + mother evening & 0.17 & 0.11 & 0.02 \\
\hline Father evening + mother day & $0.52 *$ & 0.12 & 0.18 \\
\hline Father day + mother "other" shift & 0.05 & -0.01 & 0.07 \\
\hline Father "other" shift + mother day & -0.07 & -0.01 & 0.26 \\
\hline Both nonstandard (evening or other) & -0.12 & -0.07 & 0.13 \\
\hline Sole-earning father & -0.23 & -0.12 & -0.14 \\
\hline Sole-earning mother & -0.13 & 0.22 & 0.27 \\
\hline No earners & 0.03 & 0.16 & $0.76 * * *$ \\
\hline \multicolumn{4}{|l|}{ Father race (vs. Non-Hispanic white) } \\
\hline Non-Hispanic black & -0.11 & 0.00 & $-0.66 * * *$ \\
\hline Hispanic & $-0.25 *$ & 0.11 & -0.07 \\
\hline Asian/Pacific Islander & $-0.28 * * *$ & $-0.21 *$ & -0.13 \\
\hline Other & 0.11 & 0.04 & 0.27 \\
\hline Child age (months) & 0.01 & $0.05 *$ & -0.01 \\
\hline Married & -0.12 & $-0.25 *$ & -0.17 \\
\hline Number of other children in household & $-0.09 *$ & $-0.14 * * *$ & $-0.13 * * *$ \\
\hline \multicolumn{4}{|l|}{ Mother education (vs. h.s. or less) } \\
\hline Some college & $0.19 *$ & 0.10 & -0.07 \\
\hline College graduate or more & 0.06 & -0.03 & -0.06 \\
\hline \multicolumn{4}{|l|}{ Father education (vs. h.s. or less) } \\
\hline Some college & $0.27 * * *$ & -0.06 & -0.05 \\
\hline College graduate or more & 0.06 & -0.05 & -0.12 \\
\hline Receipt of government support & -0.03 & -0.01 & 0.04 \\
\hline Support for father involvement (1-4) & & $0.56 * * *$ & $0.35 * * *$ \\
\hline Father age (years) & $-0.01 *$ & $-0.01 * *$ & 0.00 \\
\hline Child female & 0.01 & $-0.16 * * *$ & $-0.32 * * *$ \\
\hline
\end{tabular}




\begin{tabular}{lccc}
\hline Mother employed 45+ hours & $0.45^{* *}$ & 0.12 & 0.07 \\
Father employed 45+ hours & $-0.27 * * *$ & $-0.23 * * *$ & $-0.18^{* * *}$ \\
Hours in non-parental care (vs. none) & & & \\
Low (1-20) & 0.10 & -0.05 & 0.03 \\
Medium (21-40) & 0.00 & -0.06 & -0.10 \\
High (41+) & -0.07 & 0.01 & -0.02 \\
Child has special needs & -0.11 & -0.04 & -0.06 \\
Relationship conflict at prior observation & & $-0.21 * * *$ & $-0.21 * *$ \\
$(1-4)$ & & & \\
\hline$R^{2}$ & 0.13 & 0.29 & 0.40 \\
$\chi^{2}$ & $88.81 * *$ & $431.95 * * *$ & $427.71 * * *$ \\
$(\mathrm{df})$ & $(56)$ & $(193)$ & $(158)$ \\
RMSEA & 0.01 & 0.02 & 0.02 \\
\hline
\end{tabular}

\section{Measurement Model}

\begin{tabular}{|c|c|c|c|c|c|}
\hline \multicolumn{2}{|c|}{ Nine-month survey } & \multicolumn{2}{|l|}{ 24-month } & \multicolumn{2}{|l|}{ Preschool } \\
\hline $\begin{array}{l}\text { Play peek-a-boo } \\
\text { with your child }\end{array}$ & $0.46^{* * *}$ & $\begin{array}{l}\text { Play chasing } \\
\text { games }\end{array}$ & $0.68 * * *$ & $\begin{array}{l}\text { Play with toys for } \\
\text { building things }\end{array}$ & $0.69 * * *$ \\
\hline Hold him/her ${ }^{\mathrm{a}}$ & $0.81 * * *$ & $\begin{array}{l}\text { Take for ride on } \\
\text { shoulders or back }\end{array}$ & $0.66^{* * *} *$ & $\begin{array}{l}\text { Take outside for a } \\
\text { walk or to play }\end{array}$ & $0.66 * * *$ \\
\hline \multirow{2}{*}{$\begin{array}{l}\text { Tickle child, } \\
\text { blow on belly, } \\
\text { or move limbs } \\
\text { around }^{\text {a }}\end{array}$} & $0.98 * * *$ & $\begin{array}{l}\text { Play with games } \\
\text { or toys indoors }\end{array}$ & $0.80 * * *$ & & \\
\hline & & $\begin{array}{l}\text { Take outside for a } \\
\text { walk or to play }{ }^{b}\end{array}$ & $0.58 * * *$ & & \\
\hline
\end{tabular}

Note: Measurement model factor loadings are reported when the latent variable is the outcome. Factor loadings are similar when the latent variable is a lagged predictor.

"Recoded from six categories to four because very few fathers reported "not at all" or "rarely"

${ }^{b}$ Recoded from six categories to five because very few fathers reported "not at all"

$* p<.05 ; * * p<.01 ; * * * p<.001$ 
Table A4.

Standardized coefficients for model predicting warmth $(\mathrm{N}=3,650)$

\begin{tabular}{llc}
\hline Variables & 24-month & Preschool \\
\hline Warmth at prior observation & & $0.68 * * *$ \\
Joint employment schedule (vs. both day) & & \\
$\quad$ Father day + mother evening & -0.06 & 0.01 \\
Father evening + mother day & 0.07 & 0.07 \\
Father day + mother "other" shift & 0.17 & -0.03 \\
Father "other" shift + mother day & -0.13 & 0.15 \\
Both nonstandard (evening or other) & 0.27 & 0.11 \\
Sole-earning father & 0.14 & 0.12 \\
Sole-earning mother & 0.03 & -0.16 \\
No earners & -0.15 & $0.50 * * *$
\end{tabular}

Father race (vs. Non-Hispanic white)

Non-Hispanic black

$-0.13-0.03$

Hispanic

$-0.23 * * \quad 0.00$

Asian/Pacific Islander

$-0.31 * * * \quad 0.02$

Other

0.01

$0.32 *$

Child age (months)

$-0.03$

0.00

Married

$-0.05$

$-0.03$

Number of other children in household

$-0.08 * *$

$-0.06^{*}$

Mother education (vs. h.s. or less)

Some college

0.10

$-0.10$

College graduate or more

0.07

0.02 


\begin{tabular}{|c|c|c|}
\hline \multicolumn{3}{|l|}{ Father education (vs. h.s. or less) } \\
\hline Some college & 0.01 & 0.02 \\
\hline College graduate or more & -0.13 & 0.00 \\
\hline Receipt of government support & 0.05 & -0.08 \\
\hline Support for father involvement (1-4) & $0.70 * * *$ & $0.70 * * *$ \\
\hline Father age (years) & 0.00 & -0.01 \\
\hline Child female & 0.06 & 0.04 \\
\hline Mother employed 45+ hours & $-0.33 * *$ & 0.08 \\
\hline Father employed $45+$ hours & 0.07 & -0.10 \\
\hline \multicolumn{3}{|l|}{ Hours in non-parental care (vs. none) } \\
\hline Low $(1-20)$ & -0.02 & $0.16^{*}$ \\
\hline Medium (21-40) & 0.11 & $0.20 *$ \\
\hline High $(41+)$ & $0.28 *$ & 0.09 \\
\hline Child has special needs & 0.01 & 0.01 \\
\hline $\begin{array}{l}\text { Relationship conflict at prior observation } \\
(1-4)\end{array}$ & $-0.34 * * *$ & $-0.20 * * *$ \\
\hline $\mathrm{R}^{2}$ & 0.12 & 0.22 \\
\hline
\end{tabular}


Table A5.

Standardized coefficients for model predicting decision influence $(\mathrm{N}=3,650)$

\begin{tabular}{|c|c|c|c|}
\hline \multicolumn{4}{|c|}{ Structural Model } \\
\hline Variables & Nine-month & 24-month & Preschool \\
\hline Decision influence at prior observation & & $0.38 * * *$ & $0.45 * * *$ \\
\hline \multicolumn{4}{|l|}{$\begin{array}{l}\text { Joint employment schedule (vs. both } \\
\text { day) }\end{array}$} \\
\hline Father day + mother evening & 0.17 & 0.02 & 0.22 \\
\hline Father evening + mother day & -0.06 & 0.03 & 0.02 \\
\hline Father day + mother "other" shift & -0.08 & -0.03 & -0.08 \\
\hline Father "other" shift + mother day & 0.05 & 0.09 & 0.09 \\
\hline Both nonstandard (evening or other) & 0.15 & 0.13 & 0.15 \\
\hline Sole-earning father & -0.03 & -0.05 & -0.04 \\
\hline Sole-earning mother & 0.04 & $0.35^{*}$ & 0.14 \\
\hline No earners & -0.10 & 0.29 & 0.42 \\
\hline \multicolumn{4}{|l|}{ Father race (vs. Non-Hispanic white) } \\
\hline Non-Hispanic black & 0.03 & 0.10 & $0.25 *$ \\
\hline Hispanic & $-0.20 *$ & $0.19 * *$ & $0.25 * *$ \\
\hline Asian/Pacific Islander & $-0.30 * * *$ & 0.01 & -0.08 \\
\hline Other & 0.09 & 0.27 & 0.19 \\
\hline Child age (months) & -0.01 & 0.01 & 0.01 \\
\hline Married & 0.08 & -0.06 & $0.32 *$ \\
\hline Number of other children in household & -0.06 & -0.02 & -0.05 \\
\hline \multicolumn{4}{|l|}{ Mother education (vs. h.s. or less) } \\
\hline Some college & $0.24 *$ & -0.13 & -0.02 \\
\hline College graduate or more & $0.20 *$ & $-0.24 * *$ & -0.08 \\
\hline \multicolumn{4}{|l|}{ Father education (vs. h.s. or less) } \\
\hline Some college & $0.21 *$ & 0.02 & 0.03 \\
\hline College graduate or more & 0.15 & 0.05 & 0.06 \\
\hline Receipt of government support & $-0.24 * *$ & -0.06 & 0.00 \\
\hline Support for father involvement (1-4) & & $0.43 * * *$ & $0.64 * * *$ \\
\hline Father age (years) & -0.01 & 0.00 & 0.00 \\
\hline Child female & 0.01 & 0.02 & 0.00 \\
\hline
\end{tabular}




\begin{tabular}{|c|c|c|c|}
\hline Mother employed 45+ hours & 0.22 & 0.00 & -0.07 \\
\hline Father employed $45+$ hours & 0.08 & -0.07 & -0.11 \\
\hline \multicolumn{4}{|l|}{ Hours in non-parental care (vs. none) } \\
\hline Low (1-20) & -0.19 & -0.03 & 0.06 \\
\hline Medium (21-40) & -0.05 & 0.14 & $0.29 * * *$ \\
\hline High $(41+)$ & -0.05 & $0.25 *$ & 0.17 \\
\hline Child has special needs & 0.04 & -0.03 & 0.07 \\
\hline $\begin{array}{l}\text { Relationship conflict at prior observation } \\
(1-4)\end{array}$ & & $-0.36 * * *$ & $-0.37 * * *$ \\
\hline $\mathrm{R}^{2}$ & 0.10 & 0.12 & 0.33 \\
\hline $\begin{array}{l}\chi^{2} \\
\text { (df) }\end{array}$ & & $\begin{array}{l}134.68 * * \\
(95)\end{array}$ & $\begin{array}{l}532.18 * * * \\
(229)\end{array}$ \\
\hline RMSEA & & 0.01 & 0.02 \\
\hline
\end{tabular}

\section{Measurement Model}

24-month survey Preschool survey

\begin{tabular}{llll}
\hline Discipline & $0.71 * * *$ & Discipline & $0.74 * * *$ \\
Nutrition & $0.82 * * *$ & Nutrition & $0.86 * * *$ \\
Health care & $0.92 * * *$ & Health care & $0.92 * * *$ \\
Child care & $0.88 * * *$ & Child care & $0.78 * * *$
\end{tabular}

Note: Measurement model factor loadings are reported when the latent variable is the outcome. Factor loadings are similar when the latent variable is a lagged predictor.

$* p<.05 ; * * p<.01 ; * * * p<.001$ 